\title{
Cosmic rays, clouds and climate
}

\section{Svensmark, Henrik}

\section{Published in:}

Europhysics News

Link to article, DOI:

10.1051/epn/2015204

Publication date:

2015

\section{Document Version}

Publisher's PDF, also known as Version of record

Link back to DTU Orbit

\section{Citation (APA):}

Svensmark, H. (2015). Cosmic rays, clouds and climate. Europhysics News, 46(2), 26-29. https://doi.org/10.1051/epn/2015204

\section{General rights}

Copyright and moral rights for the publications made accessible in the public portal are retained by the authors and/or other copyright owners and it is a condition of accessing publications that users recognise and abide by the legal requirements associated with these rights.

- Users may download and print one copy of any publication from the public portal for the purpose of private study or research.

- You may not further distribute the material or use it for any profit-making activity or commercial gain

- You may freely distribute the URL identifying the publication in the public portal

If you believe that this document breaches copyright please contact us providing details, and we will remove access to the work immediately and investigate your claim. 


\section{COSMIC RAYS, CLOUDS AND CLIMATE}

• Henrik Svensmark - hsv@space.dtu.dk - DOI: 10.1051/epn/2015204

- National Space Institute - Technical University of Denmark - Elektrovej, Bygning 328, 2800 Kgs - Lyngby, Denmark

The most profound questions with the most surprising answers are often the simplest to ask. One is: Why is the climate always changing? Historical and archaeological evidence of global warming and cooling that occurred long before the Industrial Revolution, require natural explanations. 


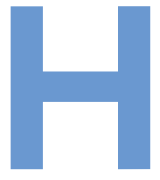

ere, the surprising answer about those never ending natural changes of climate is that galactic cosmic rays ${ }^{1}$, atomic particles coming from the supernova remnants left by exploded stars, appear to play a major part. By ionizing the air, cosmic rays help to form aerosols ${ }^{2}$ that may grow into cloud condensation nuclei (CCN), required for water droplets to condense and create low-altitude clouds. As these exert a strong cooling effect, increases or decreases in the cosmic ray influx and in cloudiness can significantly lower or raise the world's mean temperature. This is the central hypothesis.

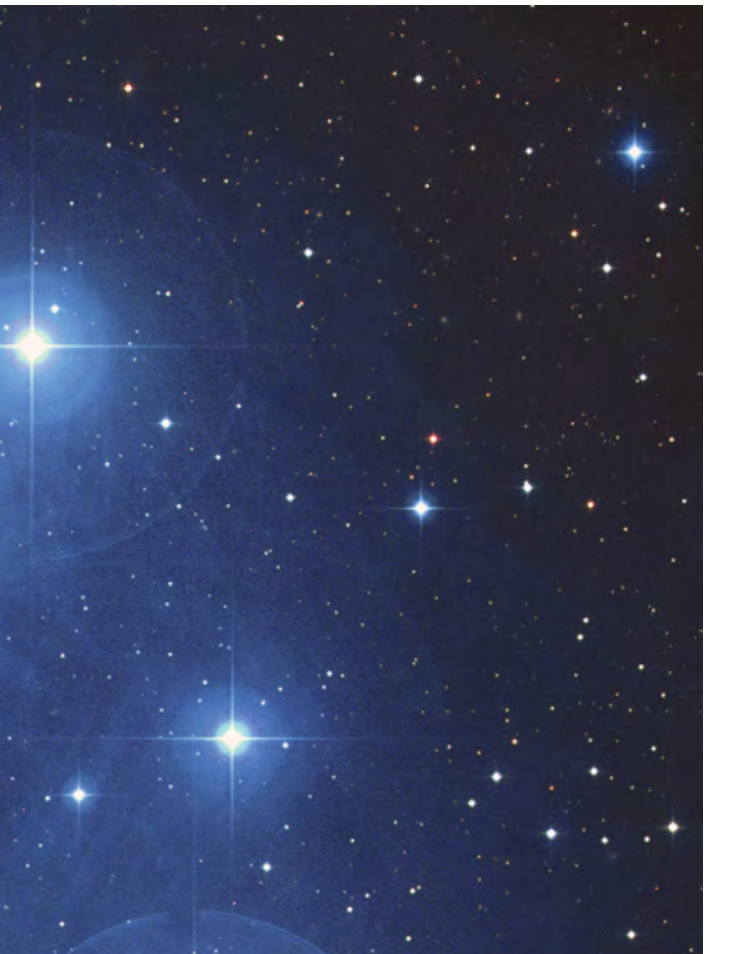

\section{Sun climate link}

In 1996 the unexpected discovery was announced that the intensity of Galactic cosmic rays incident on the Earth's atmosphere correlates closely with variations of global cloud cover [1]. It was suggested that this connection could be responsible for the observed correlations between variations in solar activity and climate. In fact there is plenty of empirical evidence of a link between solar activity and Earth's climate. One of the more beautiful results is the multi-millennial correlation between the temperature of the Indian Ocean as mirrored in the ratio between different oxygen isotopes in stalagmites in a cave in Oman, and solar activity, as reflected in the cosmogenic carbon 14 isotope [2]. In 2008 Shaviv quantified the solar climate link. Using the oceans as a calorimeter the solar forcing over the ( 11 year) solar cycle was estimated to be in the range 1.0 $-1.5 \mathrm{~W} / \mathrm{m}^{2}$. This value is $5-7$ times larger than the forcing from solar irradiance alone, and points to an amplification mechanism, that may well involve clouds [3].

So the question is, what mechanism could be responsible for a cosmic ray - cloud correlation? The ideas soon focused on the formation of aerosols and subsequently growth to $\mathrm{CCN}$, as a possible explanation. The idea could be tested experimentally and in 2006 the first results where published, which demonstrated that when ionization is increased the number of small aerosols (3 $\mathrm{nm}$ ) increased as well [4].

The immediate reactions to these results were that, although we see $3 \mathrm{~nm}$ aerosol particles formed in the experiment, they would be unimportant in the real atmosphere as there are a sufficient number of CCN already. That ions are unimportant in $\mathrm{CCN}$ formation, found further support when a number of numerical simulations of the prevailing theory pointed to a failure of growth to $\mathrm{CCN}$ (e.g. [5]). If true the cosmic ray - cloud idea would be dead.

Fortunately the theory could be tested experimentally, as was done with SKY2, the chamber of which holds $8 \mathrm{~m}^{3}$ of air and traces of other gases. One series of experiments confirmed the unfavorable prediction that the new clusters would fail to grow sufficiently to be influential for clouds. But another series of experiments, using ionizing gamma rays, gave a very different result. In this case all the additional formed small aerosols ( $3 \mathrm{~nm}$ ) grew to CCN sizes, contradicting the numerical simulations of aerosol formation and growth [6].

${ }^{1}$ Cosmic rays consist mainly of protons with energies in the range $10^{6}-10^{18} \mathrm{eV}$. The relevant energies for climate are in the range $10^{9}-10^{11} \mathrm{eV}$. Such cosmic rays are accelerated in shock fronts of supernovae.

${ }^{2}$ Aerosols are $0.001-1 \mu \mathrm{m}$ diameter particles of liquid or solid suspended in the air. Aerosol concentrations vary typically from $\sim 100 \mathrm{~cm}^{-3}$ in maritime air to $\sim 1000 \mathrm{~cm}^{-3}$ in unpolluted air over landmasses, but there are large variations from these values. Aerosols larger than $\sim 0.05 \mu \mathrm{m}$ can serve as cloud condensation nuclei. of the Pleiades, the nearest open stellar cluster, 490 light-years away and formed together as a large group.
4 Hubble picture 

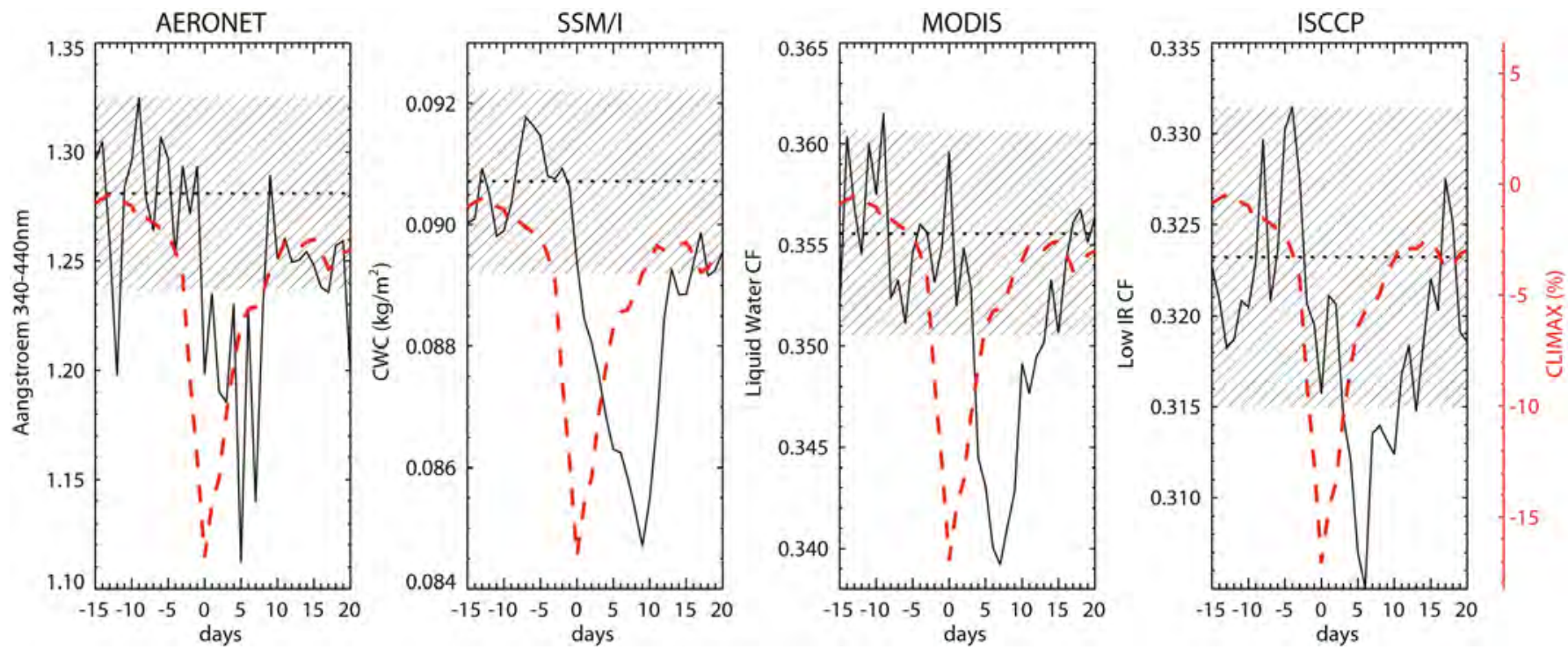

$\triangle$ FIG. 1: The daily averages of aerosol and cloud parameters preceding and during

Forbush decreases

in the cosmic ray

flux (red dashed

curve), averaged

over the 5 strongest

events between

1987 and 2005 , (a)

The Aangstroem

exponent from

the AERONET data

(indicating the

density of aerosols

in the atmosphere)

(b) cloud water

content over the

oceans (SSM/I data),

(c) liquid water cloud

fraction (MODIS

data), and (d) low

IR-detected clouds

(ISCCP data). From [7]

\footnotetext{
${ }^{3}$ Regions of high star formation are also regions where stars of masses more than 8 times the mass of our Sun can form. Such massive stars end their lives after a relatively short time as supernovae. Since the supernova shock fronts are the accelerators of cosmic rays, temporal variation in the number of supernovae in the solar neighbourhood translates into variations in the cosmic ray flux on million year time scales.

${ }^{4} \mathrm{~A}$ loose, irregular grouping of stars held together by gravity that originated from a single molecular cloud. Open stellar clusters typically contain from a hundred to several thousand stars and are confined to the disk of the galaxy. The Pleiades is the best-known open cluster.
}

\section{Link to the Milky Way}

For some years it has been a contentious issue whether our planet's ever-changing location in the Milky Way Galaxy and associated variations in the influx of cosmic rays have influenced its climate and life over geological time scales. More than ninety years ago the astrophysicist Shapley suggested that ice ages on the Earth might be due to the Solar System's encounters with gas clouds in the Milky Way. A more comprehensive scenario from Shaviv [8] linked icy episodes on the Earth during the Phanerozoic Eon (last $542 \mathrm{Myr}$ ) to the Solar System's encounters with spiral arms of the Milky Way as it orbited around the Galactic centre. As spiral arms are regions of increased star formation ${ }^{3}$ and therefore also the heavy stars that become supernovae, they are regions of elevated galactic cosmic rays.

At first sight it seems unlikely that processes in remote space should have a large influence on Earth. However, during the last decade the evidence has been accumulating. A recent example is based on open star clusters in the solar neighbourhood, from which the supernova history during the last 500 million years was constructed [9]. Open stellar clusters ${ }^{4}$ in our stellar neighbourhood, born together many millions of years ago, have ages that clump together at times of high star formation rates, corresponding with our planet's encounters with the bright star forming regions of the Milky Way. These are the scenes of intense star formation, including massive stars that explode as supernovae and shower our planet with energetic Galactic cosmic rays. At such times the Earth was cold, because cosmic rays promote cloud formation that reduces sunshine at the surface. In darker regions of the Milky Way, between the star forming regions, the Earth was warm - far hotter than today. Fig. 2 shows the supernova rate reconstructed from open stellar cluster in the solar neighbourhood during the last 500 million years (red curve). The variations in supernovae rate over this period correlate with the variations in climate. The colored band on top indicates climatic periods: warm periods (red), cold periods (blue), glacial periods (white and blue hatched bars) 
- FIG. 2: Red curve is the variation in the local supernova rate, and therefore also the variation in cosmic ray flux during the last $\mathbf{5 0 0}$ Myr. The colored band indicates climatic periods: warm periods (red), cold periods (blue), glacial periods (white and blue hatched bars) and finally peak glaciations (black and white hatched bars). The proportions of carbon-13 in sediments $\left(d^{13} \mathrm{C}\right.$ in parts per mill) over the past 500 Myr, shown in the scattered points, reflect changes in the carbon cycle. $\mathrm{d}^{13} \mathrm{C}$ carries information on the burial of organic material in sediments, and is therefore a record of bio-productivity. Blue dashed curve is smoothed $d^{13} \mathrm{C}$. Circles are $\mathrm{d}^{13} \mathrm{C}$ from marine carbonates, open circles with a star symbol, Jurassic to Neogene, are a carbon isotopic record of organic matter. Note that there are three brief gaps in the $\mathrm{d}^{13} \mathrm{C}$ data (end-Silurian, mid-Carboniferous and mid Jurassic). Abbreviations for geological periods are $\mathrm{Cm}$-Cambrian, 0-Ordovician, S-Silurian, D-Devonian, C-Carboniferous, P-Permian, $\mathrm{Tr}$ - Triassic, J- Jurassic, $\mathrm{K}$ - Cretaceous, $\mathrm{Pg}$-Palaeogene, $\mathrm{Ng}$ - Neogene. Figure based on Ref. [9].

and finally peak glaciations (black and white hatched bars). Note the correspondence between high supernovae activity and cold/glacial climate (for more information see, Ref. [9]).

But it is not just climate that is affected. Life on Earth responds to climatic variations. The effects are counter-intuitive, with the most generous bio-productivity occurring in the cold intervals associated with the star forming regions. Figure 2 compares this cosmic ray history (red curve) with a carbon-13 isotope history obtained from marine sediments (grey symbols, blue dashed curve smoothed carbon-13). Carbon-13 follows changes in the carbon cycle and carries information on the burial of organic material in sediments, and of bio-productivity, and so it also reflects the overall condition of life on Earth.

Despite the large variability in carbon-13 in each time interval, the influence of the supernova rate plainly overrides all the complex practical and theoretical reasons why such coherence with carbon-13 might not be expected.Life's connection to supernova rate does not stop with the bio-productivity. Even $\mathrm{CO}_{2}$ concentration in the atmosphere and genus-level diversity of extant and extinct marine-invertebrates as an index of variable biodiversity also show a remarkable connection to variable SN rates. (See Fig. 20 and 21 in Ref. [9])

Since the supernova variation reflects variation in star formation and the morphology of our Galaxy's spiral arms one ends up with the surprising result that the conditions for life on Earth are a reflection of the shape of the Milky Way.

\section{Conclusion}

A surprising consistency exists between variations in cosmic ray flux and variations in climate and is a motivation for continued research. It is seen on nearly all timescales ranging from days to millions of years. As for palaeo-biology, remarkable connections to the long-term history of life and the carbon cycle have shown up unbidden. Biodiversity and bio productivity $\left(\mathrm{d}^{13} \mathrm{C}\right)$ all appear so highly sensitive to supernova in our Galactic neighborhood that the biosphere seems to contain a reflection of the sky.

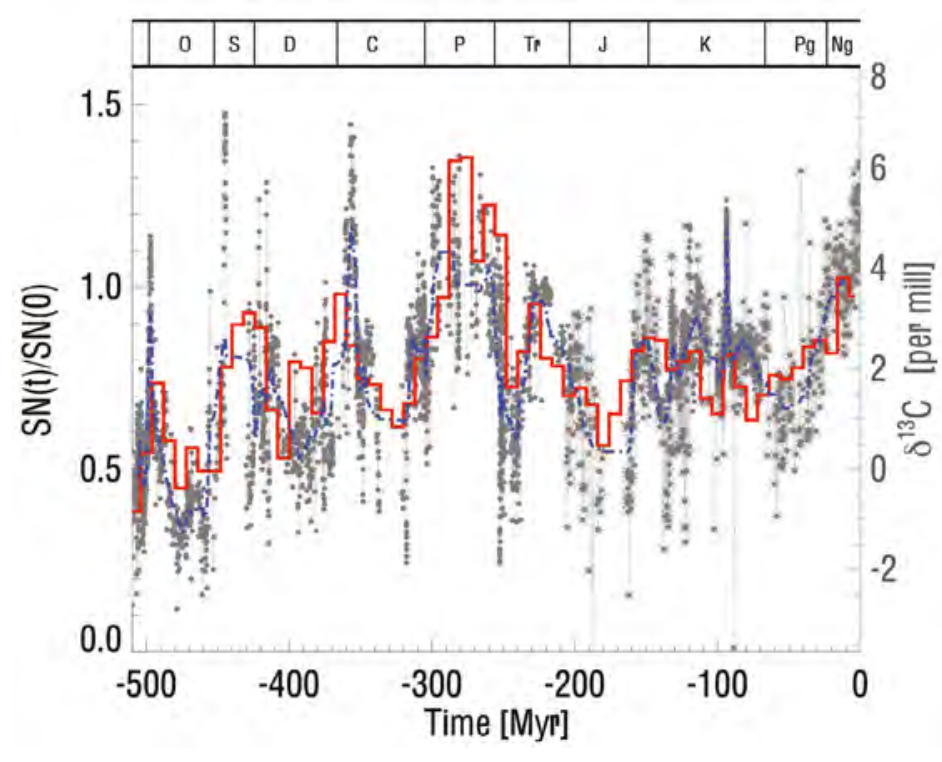

\section{About the Author}

Henrik Svensmark (born 1958) is a physicist and professor in the Division of Solar System Physics at the Danish National Space Institute (DTU Space). He held postdoctoral positions in physics at three other organizations: University of California, Berkeley, Nordic Institute for Theoretical Physics, and the Niels Bohr Institute.

\section{References}

[1] H. Svensmark and E. Friis-Christensen, 'Variation of cosmic ray flux and global cloud coverage-a missing link in solar-climate relationships', J. Atmos. Terr. Phys. 59, 1225 (1997)

[2] U. Neff et al.,'Strong coherence between solar variability and the monsoon in Oman between 9 and 6 kyr ago', Nature 411, 290 (2001)

[3] N. J. Shaviv, 'Using the oceans as a calorimeter to quantify the solar radiative forcing' J. Geophys. Res. 113, 2156 (2008)

[4] H. Svensmark, J. O. P. Pedersen, N. D. Marsh, M. B. Enghoff and U. I. Uggerhøj, 'Experimental evidence for the role of ions in particle nucleation under atmospheric conditions', Proc. $R$. Soc. London Ser. A 463, 385 (2007)

[5] J. R. Pierce and P. J. Adams, 'Can cosmic rays affect cloud condensation nuclei by altering new particle formation rates?' Geophys. Res. Lett. 36, L09820 (2009)

[6] H. Svensmark, M. B. Enghoff and J. O. P. Pedersen, 'Response of cloud condensation nuclei ( $>50 \mathrm{~nm}$ ) to changes in ion-nucleation', Phys. Lett. A 377, 2343 (2013)

[7] H. Svensmark, T. Bondo and J. Svensmark, 'Cosmic ray decreases affect atmospheric aerosols and clouds', Geophys. Res. Lett. 36, L15101 (2009)

[8] N. J Shaviv. 'The spiral structure of the Milky Way, cosmic rays, and ice age epochs on Earth', New Astron., 8, 39-77 (2003)

[9] H. Svensmark, 'Evidence of nearby supernovae affecting life on Earth', Mon. Not. R. Astron. Soc., 81, 5027 (2012)

\section{Suggestion for further reading}

H. Svensmark and N. Calder, 'The Chilling Stars: A New Theory of Climate Change', published in UK, US, Australia by Icon Books: www.iconbooks.co.uk- ISBN=1-84046-815-7, 246 pages. (2007) 